\title{
AS POSSIBILIDADES PEDAGÓGICAS NO ENSINO DE METODOLOGIA DA PESQUISA CIENTÍFICA EM CIÊNCIA DA INFORMAÇÃO E OS OBJETOS DESTE CAMPO CIENTÍFICO:
} aproximações Durkheimianas

\author{
THE PEDAGOGICAL POSSIBILITIES IN THE EDUCATION OF SCIENTIFIC \\ RESEARCH METHODOLOGY IN INFORMATION SCIENCE AND THE \\ SCIENTIFIC OBJECTS OF THIS FIELD: Durkheim approaches
}

Francisco das Chagas de Souza, Doutor Professor do Departamento de Ciência da Informação Universidade Federal de Santa Catarina chagas@,cin.ufsc.br

\begin{abstract}
RESUMO
Resultado de pesquisa bibliográfica, exploratória e qualitativa, o texto argumenta que três enfoques estão presentes no processo educacional das disciplinas de Metodologia da Pesquisa Científica em Ciência da Informação, ou seja, a partir dos fatos sociais da Ciência da Informação, da tipologia da pesquisa e da teoria social. Defende a idéia de que há uma relação direta entre o ensino / aprendizagem da Metodologia Científica e as condições educacionais e de infra-estrutura informacional ofertadas no ensino fundamental e médio. Vê que as possibilidades pedagógicas do ensino de Metodologia Científica em Ciência da Informação estão relacionadas com a prática da escrita a qual depende da prática da leitura.
\end{abstract}

PALAVRAS-CHAVE: Ensino de Metodologia científica. Pesquisa em Ciência da Informação. Objeto científico na Ciência da Informação.

\section{INTRODUÇÃO}

Há uma discussão potencial que precisa ser inserida nos estudos desenvolvidos no campo da Ciência da Informação realizados no Brasil. Ela diz respeito à noção de Metodologia da Pesquisa. Essa potencialidade não significa ausência de debate, ao contrário, como pode ser exemplificado a partir da existência de trabalhos com a profundidade dos apresentados por González de Gómez (1999/2000). Contudo, é perceptível que este debate deve passar por um maior alargamento buscando um alcance mais amplo do que o até aqui obtido. Constata-se que o tema vem sendo objeto de interesse tanto da ANCIB (Associação Nacional de Pesquisa e Pós-Graduação em Ciência da Informação) quanto da ABECIN (Associação Brasileira de Ensino em Ciência da Informação) e, cotidianamente, está nas preocupações tanto dos docentes dos programas de pós-graduação em Ciência da Informação quanto dos docentes dos Cursos de Graduação que se articulam ao campo mais amplo da Ciência da Informação, ou seja, Arquivologia, Biblioteconomia, Gestão da Informação, por 
exemplo. Contudo, nos distintos níveis de atuação acadêmica que organizam o ensino deste amplo campo, não parece estar tão evidente o que constitui a razão de ser da pesquisa ou, para recuperarmos a fórmula Durkheimiana, de quais coisas ou de quais fatos parte-se, na Ciência da Informação, para identificar fenômenos carentes de investigação e constituir objetos para deles extrair novas respostas para as necessidades coletivas.

Se for possível considerarmos aceita a idéia de que a Ciência da Informação é uma das várias Ciências Sociais, como se vê na argumentação de Carvalho (1999), apoiado em Foskett, a quem cita na página 56 de seu texto, pode-se perguntar quais são os fatos sociais que produzem os fenômenos geradores de objetos de pesquisa que ocupariam os estudiosos do campo. Esta é uma pergunta fundamental, capaz de apontar a reflexão para a identificação de metodologias de pesquisa a serem ensinadas, assimiladas, transformadas e empregadas tanto para estudos no ensino de graduação quanto na execução das investigações inerentes ao que fazer na pós-graduação stricto sensu.

Evidentemente, a discussão comporta vários enfoques, além do acima referido. Um segundo enfoque, então, tem relação com a tipologia da pesquisa e aqui cabe uma presença mais imediata em nossa discussão dos metodologistas, como sistematizadores e divulgadores das múltiplas possibilidades metodológicas que se encontram evidenciadas nos relatórios e em artigos originados de pesquisa científica. Um terceiro enfoque pode estar relacionado mais intensamente com a teoria social e suas diversas correntes que se constituem com a finalidade de analisar os fenômenos produzidos socialmente.

Este artigo tem por objetivo discutir esses três enfoques com a expectativa de contribuir com a discussão do processo educacional e de investigação desenvolvido nos Cursos do campo da Ciência da Informação no Brasil e, além disso, fomentar a discussão que possa levar ao aclaramento das dificuldades manifestadas pelos estudantes quando tentam identificar quais os tipos de pesquisa que podem ser enunciados para classificar as investigações em desenvolvimento em dado momento.

O texto que se segue resulta de uma pesquisa do tipo bibliográfico (quanto à fonte de coleta dos dados), exploratória (quanto ao seu objetivo) e qualitativa (quanto à forma como o material obtido foi analisado).

\section{FATO E FENÔMENO SOCIAL NA “CIÊNCIA DA INFORMAÇÃO”}

Em Durkheim fato social é "toda maneira de fazer, fixada ou não, suscetível de exercer sobre o indivíduo uma coerção exterior: ou então, que é geral no âmbito de uma dada 
sociedade tendo, ao mesmo tempo, uma existência própria, independente das suas manifestações individuais." (DURKHEIM, p. 40).

Pode-se entender da definição acima que, embora sendo criadas pelas ações humanas, as circunstâncias coletivamente estabelecidas, em quaisquer situações, produzem fatos sociais na medida em que estes podem afetar a todos os indivíduos. Deste ponto de vista, pode-se encontrar na Ciência da Informação um razoável número de fazeres, com jeitos particulares de se manifestar, os quais exercem sobre os pensadores, trabalhadores e usuários do conhecimento teórico e prático elaborado no âmbito da Ciência da Informação, e nos seus modos de atuar e pensar, uma pressão externa que se pode dizer como própria do campo. Explicitamente, o conhecimento teórico que vem sendo produzido pelo campo reforça este entendimento. Tome-se o mais consolidado elenco de representação científica produzido no campo: as Cinco Leis da Biblioteconomia, de Ranganathan, e explore-se o pensamento do autor sobre as suas observações, seus experimentos, o tratamento de raciocínio que emprestou à construção desta explicação contingente (RANGANATHAN, 1965). Nas Leis de Ranganathan, que são regularidades ou representações produzidas por um coletivo social, encontram-se os fatos sociais e os fenômenos que a progressiva construção de meios materiais ofereceu para que a interação humana não-biológica se aperfeiçoasse ao longo das gerações dos últimos quatro mil anos, ou seja, no período histórico escritural.

As cinco Leis de Ranganathan, para revermos, afirmam: 1 - Livros existem para serem usados; 2 - A cada leitor o seu livro; 3 - Para cada livro e seu leitor; 4 - Poupe o tempo do leitor; 5 - A biblioteca é uma organização em crescimento.

Um exame dos termos utilizados por Campos para sintetizar o significado de cada uma dessas Leis, e a maneira de apresentá-las utilizada por Ranganathan (1965) aponta, pelo menos, para sete fatos sociais que se desdobram em fenômenos ou blocos temáticos. Esses blocos têm um grande potencial de geração de objetos de pesquisa que, uma vez construídos e explorados, podem superar as tentativas de leitura que querem encontrar grandes objetos específicos no campo da Ciência da Informação como faz Dias (2002) que, neste esforço e no artigo referido, se apóia em outros estudiosos igualmente diligentes.

A figura 1 abaixo arrola sete fatos sociais que permeiam o campo da Ciência da Informação e os correspondentes fenômenos ou blocos temáticos que deles derivam: 
FIGURA 1

\begin{tabular}{|l|l|c|}
\hline FATOS SOCIAIS DA CI & FENÔMENOS OU BLOCOS TEMÁTICOS & OBJETOS DE PESQUISA \\
\hline Leitura & Decodificação de conhecimento social & $!$ \\
\hline Comunicação & Interação social permanente & $!$ \\
\hline Conhecimento & $\begin{array}{l}\text { Produção interpretativa e empírica como resposta a } \\
\text { necessidades coletivas }\end{array}$ & $!$ \\
\hline Educação & $\begin{array}{l}\text { Aquisição de conhecimento simbólico controlado } \\
\text { socialmente }\end{array}$ & $!$ \\
\hline Memória & Estoque de conhecimento & $!$ \\
\hline Política & Ordenamento e controle das necessidades coletivas \\
\hline Economia & $\begin{array}{l}\text { Regulação de acesso material ou físico à memória, } \\
\text { educação, conhecimento e comunicação }\end{array}$ \\
\hline
\end{tabular}

A figura 1 acima, provisoriamente, omite enunciados referentes a objetos de pesquisa gerados a partir dos fatos sociais e dos fenômenos ou blocos temáticos da Ciência da Informação. Há várias razões para isso, como por exemplo: a) o fato de que a maior parcela de discussão realizada neste vasto campo limita-se às tentativas de mostrar o que se deve pesquisar, quais são os temas a explorar, o que se deve aprofundar; b) a dinâmica da sociedade, especialmente, em seus meios científicos, técnicos e sócio-político-educacionais cria e inova exaustivamente os mais variados temas para estudo. Na perspectiva colocada pela razão a acima, vê-se no artigo Moraes (2002) que a história dos pioneiros da Ciência da Informação, produz uma síntese de conhecimentos que se consolida sob a forma das disciplinas que lhes agrega e compõem uma face visível do campo. Ali, os trabalhos dos pioneiros estão agrupados no quadro 1 de seu texto, ordenado em 11 temas. Para compor seu texto a autora baseou-se em artigo anterior de Pinheiro e Loureiro (1995), também resgatado em outro texto de Pinheiro (1999). Os enunciados ali expostos hoje não apenas representam parte das áreas de concentração dos programas de Pós-Graduação em Ciência da Informação, e mesmo da graduação, mas também definem nomes de disciplinas curriculares no ensino de graduação, senão veja-se:

. Sistemas de recuperação da informação;

. Informação em ciência e tecnologia;

. Tecnologias da informação;

. Representação da informação;

. Administração e processos técnicos de sistemas de informação;

. Epistemologia da Ciência da Informação:

. Abstracts;

. Redes e sistemas de informação;

. Informação social e política; 


\section{. Usuários;}

. Economia da informação. (MORAES, 2002)

No IV Encontro Nacional de Pesquisa e Pós-Graduação em Ciência da Informação, realizado Brasília, no ano 2000, várias contribuições demonstram a diversidade de percepção sobre os objetos de investigação do campo. No trabalho de Miranda e Barreto, que diagnostica e prognostica a Pesquisa em Ciência da Informação no Brasil, há um quadro 1 no qual os autores caracterizam 5 grandes grupos de pesquisa em Ciência da Informação. A partir dessa caracterização, os autores procuram extrair uma síntese da evolução quantitativa da pesquisa no campo pela análise dos trabalhos e artigos publicados, apresentados e encaminhados ao III Enancib (1997), artigos de 1997 a 2000 da revista Ciência da Informação e trabalhos encaminhados para apresentação no próprio IV Enancib. Esses 5 grandes Grupos são:

. Informação e contexto;

. Organização da informação;

. Informação tecnológica;

. Novas tecnologias de informação e comunicação;

. Aspectos teóricos da ciência da Informação. (MIRANDA; BARRETO, 1999/2000).

O texto apresentado por Mueller; Miranda e Suaiden, no mesmo evento, traz outro agrupamento, agora com base exclusiva nos trabalhos apresentados nos 4 Encontros (ENANCIB), isto é, os três anteriores e o então em andamento. Com pequenas variações, identifica no IV Enancib a existência de produção que pode ser reunida em 8 grupos temáticos:

\section{. Informação tecnológica;}

. Representação do conhecimento, indexação, teoria da classificação;

. Novas tecnologias, bases de dados, fontes de informação e a educação a distância;

. Informação e sociedade, ação cultural;

. Comunicação científica;

. Formação profissional, mercado de trabalho;

. Planejamento de sistemas, inteligência competitiva;

- Epistemologia da Ciência da informação. (MUELLER; MIRANDA; SUAIDEN, 1999/2000). 
Outro trabalho debatido no IV Enancib, de Ramirez Leyva sobre a pesquisa em Biblioteconomia na América Latina traz o quadro 3 que oferece uma comparação dos temas pesquisados em 1995 e 2000. Segundo a autora, em 2000 foram pesquisados:

. Automação;

. Administração;

. Usuários;

. História;

. Linguagens;

. Educação Bibliotecária;

. Serviços de informação;

. Tecnologia da informação;

. Desenvolvimento de coleções;

. Sistemas e serviços de informação;

. Organização da informação;

. Produtividade e comunicação científica;

. Sociedade da informação;

. Biografias;

. Patrimônio documental;

. Leitura;

. Teoria da Biblioteconomia;

. Arquivos históricos e Uso da informação.

Os temas apontados, nesta comunicação, como relativos a 1995 apresentam um nível de agregação maior, no entanto indicam da mesma maneira a diversidade que a percepção de objetos a pesquisar determina aos investigadores da Ciência da Informação na região (RAMIREZ LEYVA, 1999/2000).

O trabalho de Pinheiro apresentado naquele mesmo evento, isto é, IV Enancib, reportando-se a uma análise do conteúdo dos artigos da revista Ciência da Informação, referentes aos anos de 1997 a 1999, exibe questões que, do seu ponto de vista, permitem identificar o que vem sendo pesquisado no campo:

. Inteligência competitiva e gestão do conhecimento;

. Sistemas / serviços de informação e bases de dados;

. Bibliotecas virtuais e digitais;

. Bibliometria / Cientometria e indicadores de C\&T; 


\section{. Informação tecnológica-industrial e para negócios;}

. Periódicos científicos, inclusive eletrônicos;

. Ciências e profissionais da informação;

. Política de informação;

. Internet, rede e comércio eletrônicos;

. Automação e gestão de bibliotecas;

. Estudos de demanda de informação e de usuários e treinamento;

. Economia da informação;

. Produção editorial e direito autoral;

. Análise, valor agregado à informação e indexação (PINHEIRO, 1999/2000).

O que é relevante perceber nestas colaborações é o esforço que seus autores fizeram de agrupar os resultados alcançados a partir de objetos que foram eleitos para a pesquisa em Ciência da Informação no Brasil e na América Latina. No entanto, e essencialmente, fica a questão de como se percebe a organicidade do conjunto desta produção e de como ela poderia ser, didaticamente, organizada para efeito de orientar a leitura e formação de novos pesquisadores capazes de, em etapas sucessivas, evoluírem mais rapidamente no processo que começa com a Iniciação Científica e alcança o pós-doutoramento, em uma desejável e crescente produção de conhecimento no campo.

A questão colocada no parágrafo acima não tem a pretensão de minimizar a conduta da formação de novos pesquisadores em Ciência da Informação, contudo é preciso realizar-se mais esforços de reflexão visando construir aproximações teóricas que permitam identificar as sistematizações que os fatos sociais da Ciência da Informação e seus fenômenos ou blocos temáticos pesquisados, sobretudo no Brasil, oferecem para os graduandos e pós-graduandos dos Cursos relacionados à Ciência da Informação poderem evoluir com mais segurança nos seus esforços de formação para a investigação.

\section{TIPOS DE PESQUISA APLICÁVEIS AO ESTUdO DOS OBJETOS DA CIÊNCIA DA INFORMAÇÃO}

A literatura de Ciência da Informação tem, sobre a defesa da discussão científica e metodológica, muitos autores significativos e a produção intelectual ou pensamento de vários deles repercute na América Latina e no Brasil. Dois, dentre os norte-americanos, chegaram a servir como referência para a problematização e a investigação. Butler, um dos primeiros 
doutores do primeiro Doutorado em Biblioteconomia criado nos Estados Unidos, na Universidade de Chicago, alertava aos bibliotecários da necessidade de sair do mundo só da prática para o mundo da ciência. Afirmava que as explicações sobre os fenômenos associados às atividades do campo precisariam ser conhecidas. Seu referencial de pesquisa, segundo a visão da época, era predominantemente das ciências naturais, e afirmava e enfatizava exaustivamente, uma racionalidade quantitativa da pesquisa científica. Seu livro $A n$ introduction to library science, originalmente escrito em 1933, tratava também dos aspectos humanísticos que ele designou como os problemas: sociológico, psicológico e histórico a constituir-se como fontes dos fenômenos ou blocos temáticos que interessava investigar. Goldhor, um dos atuais Professores Eméritos da Universidade de Illinois, em Urbana, foi autor do livro An introduction to scientific research in librarianship, originalmente publicado em edição restrita, em 1969, e mais tarde, em 1972, em edição comercial pela Escola de Biblioteconomia da Universidade de Illinois, conforme informações colhidas no site http://web.library.uiuc.edu/ahx/uasfa/1801028.pdf e que teve imediata edição brasileira em 1973. Este livro foi elaborado como um manual de orientação para a pesquisa científica em Biblioteconomia. Nas palavras do autor, corresponderia a algumas lições que ele transmitia a seus alunos na Escola de Biblioteconomia da Universidade de Illinois sobre o que é importante para a formulação e execução de uma pesquisa. A própria estrutura do livro, em três partes, contém: 1 - lições sobre a logicidade de uma pesquisa científica; 2 - algumas formas de coleta e análise de dados, em que ele tece considerações sobre o que chama de pesquisa histórica, pesquisa descritiva, métodos estatísticos, pesquisa experimental e a análise e interpretação; e 3 - uma bibliografia recomendada. Em seu contorno mais geral, também em termos da época (final dos anos 1960), as propostas e a visão de pesquisa apresentada no livro é elementar. Talvez pelo fato de refletir ainda pouco da Ciência da Informação que, na época, conforme uma certa literatura, segundo Mueller (2000), ainda estava nos seus inícios, esta obra não incorpora toda a complexidade que as análises inseridas pela teoria social na Biblioteconomia e Ciência da informação viriam a trazer. De outro lado, a própria apresentação do Editor, Abner Lellis Vicentini, aponta que "trata-se da primeira obra destinada à comunidade luso-brasileira enfocando a problemática da pesquisa científica nos campos da biblioteconomia e da documentação" (GOLDHOR, 1973, p. 9). Isso dá a idéia do alcance introdutório que a obra apresentava e, portanto, a razão de ser de sua tradução e publicação no Brasil

De outro lado, pode-se verificar no campo da ciência da informação, que hoje se vive uma situação de muito maior avanço, o que torna possível enxergar muito mais 
complexidades. Em face disso, passou a ser uma necessidade a formulação de uma tipologia ou classificação mais objetiva que, efetivamente, facilite aos estudantes assimilarem enunciados representativos dos tópicos ou aspectos que estão sendo tomados para ordenar as classes ou tipos de pesquisa. Assim, uma busca na literatura metodológica, ou de sistematização do discurso metodológico, proporcionará aos estudantes um nível maior de segurança quando precisarem referir-se acerca do tipo de pesquisa que fazem ou pretendem fazer. Uma comparação entre algumas das obras existentes leva a perceber que, em geral, dáse o cruzamento de mais de um daqueles tipos de pesquisa num mesmo projeto.

A título de exemplo, uma obra, dentre as tantas outras, que auxilia os estudantes de graduação de várias escolas no Brasil - conforme programas de ensino da disciplina metodologia científica, ou disciplinas similares, localizados em busca realizada na Internet, no início de junho de 2003 - tem o título Como elaborar projetos de pesquisa de Gil, da qual já saíram algumas edições. Nela o interessado encontrará um capítulo intitulado "Como classificar as pesquisas" que dá uma base bastante segura. O autor estabelece dois grupos de tipificação. No primeiro considera que as pesquisas podem ser classificadas tendo por base os objetivos perseguidos pelo pesquisador, ou seja, o que o interessado deseja alcançar ao planejar a sua pesquisa: 1 - explorar o objeto que tem em mãos; 2 - buscar explicações sobre determinadas manifestações fenomênicas do objeto ou, por fim, 3 - descrever um objeto em suas particularidades. No segundo grupo considera que as pesquisas podem ser classificadas tendo por base os procedimentos técnicos definidos pelo pesquisador tendo em vista os objetivos pretendidos, o objeto que constituiu a partir de um dado tema, o meio ou contexto imediato onde se realizará a pesquisa, o tempo e os recursos de que pode dispor em termos de suporte materiais e humanos. Ou seja, neste grupo a classificação está centrada no conjunto de fatores operacionais referente ao como fazer a pesquisa, isto é, tem por base a metodologia da pesquisa, de tal sorte que a classificação se distingue pela fonte ou pelo modo como se trabalha esta fonte: 1 - é uma pesquisa bibliográfica; 2 - é uma pesquisa documental; 3 uma pesquisa experimental; 4 - uma pesquisa ex-post-facto; 5 - um levantamento; 6 - um estudo de caso; 7 - uma pesquisa-ação; 8 - uma pesquisa participante. Na terceira edição de seu livro, Gil (1996) faz uma detalhada orientação para cada um desses tipos de pesquisa. Desse modo, é possível ao interessado perceber que uma pesquisa exploratória quanto ao objetivo pode ser bibliográfica, ou documental, ou pesquisa-ação quanto à fonte e ao modo de captação do material, ou seja, quanto às técnicas e instrumentos utilizados para resgatar os dados. 
Entretanto, existe um terceiro jeito de expressar a tipificação da pesquisa que está presente nas modalidades acima apresentadas por Gil (1996) mas que ele não a explicita claramente e que, nas últimas décadas, tem estado presente na classificação das pesquisas realizadas nas ciências sociais. Esse grupo enuncia pesquisas quantitativas, qualitativas e quali-quantitativas (HAGUETTE, 1997). Uma das fontes que poderia ser utilizada para orientar esta discussão e minimizar as dúvidas dos estudantes é o livro Pesquisa social de Minayo e outros. Contudo, o que há de objetivo nesta classificação é o fato de que ela está fazendo referência a maneira como o pesquisador trata, analisa ou interpreta seus dados, isto é, 1 - quantitativo: dando maior ênfase ao uso da estatística deixando-a dirigir a análise e interpretação e buscando formular generalizações a partir dos resultados obtidos; 2 - qualiquantitativo: utilizando a estatística como mais um dos recursos para o tratamento e interpretação do conjunto de material coletado e disponível para chegar a conclusões sem forçar generalizações a partir dos resultados obtidos; e 3 - qualitativo - fazendo o tratamento e interpretação do conjunto de material disponível por meio de processos hermenêuticos a partir do que busca extrair dos discursos a expressão da subjetividade do sujeito informante ou a percepção obtida pela participação do pesquisador em processos de coleta com envolvimento direto ou com observação. Neste caso a classificação é realizada também tendo por base a metodologia da pesquisa mas no aspecto do tratamento e análise.

Assim, percebe-se que toda a discussão relativa à classificação da pesquisa centra-se no olhar para os objetivos pretendidos pelo investigador e na metodologia (material, métodos e procedimentos de análise) empregada.

É a partir destes dois grandes aspectos que se pode analisar a trajetória da discussão na Ciência da Informação. A propósito, a edição do periódico Library Trends, volume 46, número 4, da primavera de 1998, editado por Gillian M. McCombs e Theresa M. Maylone, trouxe como conteúdo a temática Pesquisa Qualitativa. Num certo sentido, em face do periódico onde está publicado, pode-se dizer que a partir de então a Pesquisa Qualitativa em Ciência da Informação, ganha validade internacional. Contudo, o significativo para este artigo é como, na apresentação do conteúdo, as editoras afirmam o que é esta classe de pesquisa: “ $A$ pesquisa qualitativa, do modo como os artigos desta edição do Library Trends a discute e fornece exemplos de sua prática, diz respeito a "maneiras de enxergar". O objetivo da pesquisa, o que quer sua metodologia, é a compreensão que obtém através de um processo de descoberta. O que está expresso na pesquisa qualitativa é um processo de descoberta que afirma convicções particulares de como o conhecimento é percebido e adquire uma 
epistemologia particular, especialmente do conhecimento de interações sociais humanas complexas "*.

Essa forma de afirmar o que deve ser entendido por pesquisa qualitativa associa, tomando por base a sistematização de Haguette (1997), o resultado esperado com determinadas técnicas e instrumentos de coleta considerados típicos dessa classe de pesquisa: a observação participante, a história de vida, a entrevista, a história oral.

Neste ponto do estudo retoma-se à introdução. Ali se dizia que um terceiro enfoque na discussão considera que a questão metodológica na formação de novos pesquisadores poderia ter relação intensa com a teoria social e suas diversas correntes as quais se constituem com a finalidade de analisar os fenômenos produzidos socialmente. Isso se dá porque no momento de se interpretar os dados coletados pelos instrumentos típicos da pesquisa qualitativa há de se ter modelos de referência. A interpretação não pode sair da cabeça do pesquisador, simplesmente. As teorias sociais e psicossociais têm se constituído a partir de construção de leis, tais como as da Biblioteconomia, de Ranganathan, a fim de dar suporte para a compreensão da realidade. Se, como diz o parágrafo acima citado, das editoras de Library Trends, v. 46, n. 4, a Pesquisa Qualitativa diz respeito a "maneiras de enxergar" ou a “compreensão que se obtém a partir de um processo de descoberta", isso necessita de parâmetros que permita comparar e distinguir. Dessa maneira é que as diversas teorias sociais, construídas a partir da verificação de regularidades sociais, tomadas de vários ângulos de visão, farão parte do domínio do pesquisador a fim de que ele possa saber o que tem em mãos e saber que explicação pode extrair a partir da exploração de um objeto de pesquisa. Conhecendo as várias correntes atuais da Teoria Social (Interacionismo Simbólico, Estruturalismo, Etnometodologia, Praxiologia social, Teoria Crítica, etc) (GIDDENS e TURNER, 1999) ou, no campo sociológico, as Sociologias do Conhecimento (BERGER e LUCKMANN, 1985; RODRIGUES, JR., 2001), do Trabalho (MARKERT, 1999), das Profisssões (FREIDSON, 1998), dentre outras, o pesquisador de Ciência da Informação poderá não apenas dizer o que obteve, mas verificar igualmente se com o seu material está aportando

\footnotetext{
* "Qualitative research, in the way that the articles in this issue of Library Trends discuss it and provide examples of its practice, is about "ways of seeing." The goal of research, whatever its methodology, is understanding gained through a process of discovery. What is expressed in qualitative research is a process of discovery that asserts particular assumptions of how knowledge is perceived and acquired a particular epistemology particularly--knowledge of complex human social interactions." LIBRARY TRENDS, v. 46, n. 4, Spring 1998.
} 
contribuição explicativa nova e recriando o conhecimento teórico para o campo em sua frente qualitativa.

\section{FENÔMENOS OU BLOCOS TEMÁTICOS EM CIÊNCIA DA INFORMAÇÃO}

A dimensão desta análise certamente ultrapassa o espaço de um artigo e, por isso, aqui se traz como aceito, desde a Introdução, que a Ciência da Informação é uma das Ciências Sociais. Ao ser uma dessas ciências responde a fatos sociais (coisas a pesquisar) que sintetizam fenômenos reais apreensíveis numa multiplicidade de concretudes ou objetos que se permitem investigar. Sob esta perspectiva, a informação fenomenicamente tem um certo traço de naturalidade que perpassa a existência físico-química e biológica e seus materiais e chega ao humano pela faticidade da Leitura, Comunicação, Conhecimento, Educação, Memória, Política e Economia. Esse conjunto de fatos sociais, isto é, de exterioridades gerais produzidas pela ação do coletivo humano, constitui os fenômenos ou blocos temáticos da Ciência da Informação. Esses blocos temáticos se comportam diferentemente em momentos históricos diversos, requerendo respostas materiais ou tecnológicas distintas. Desse modo, ao ser problematizado pelo contexto, esses blocos se rompem em tantos objetos de pesquisa quanto sejam as necessidades coletivas. $\mathrm{O}$ que se observa então é uma complexidade que inviabiliza, a não ser por uma intervenção externa organizadora, e temporariamente, a produção de resposta definitiva para qualquer objeto focalizado. $\mathrm{O}$ olhar imediato sobre os blocos temáticos e os fatos sociais geradores afirma a Ciência da Informação como um campo em que todos os objetos de pesquisa buscam respostas que dependem simultaneamente das respostas obtidas para todos os demais objetos, em todos os tempos: passado, presente e futuro. Vem daí, a própria diversidade de modos de afirmar o que constitui interesse do campo. Butler, em busca do caminho para justificar a Biblioteconomia como um campo científico e sensibilizar os bibliotecários norte-americanos da década de 1930 e vindouras, dizia que "o fenômeno fundamental da profissão de bibliotecário (...) é a transmissão da experiência acumulada pela sociedade, a cada um dos seus membros, por meio da instrumentalidade do livro" (BUTLER, 1971, p. 60). Shera, segundo Dias (2002, p. 97), "certa vez identificou como sendo a tarefa do bibliotecário: maximizar a utilidade dos registros de conhecimento em benefício da sociedade”. Na sua discussão, Dias (2002) examinando o específico do campo, ao revisar vários autores, encontra outras percepções sobre o objeto: orientação para o usuário; uso da informação; satisfação das necessidades individuais de informação, etc. Barreto, em entrevista concedida a Leonardo Melo, ao ser perguntado 
"Dadas as atuais características da Ciência contemporânea, será que pode haver dúvidas de que a informação é o objeto de estudo da Ciência da Informação?", responde: "Realmente não sei. Tenho que pensar primeiro no que considero o objeto da ciência da informação". (BARRETO, s.d.; s.p.). Ora, tudo isso talvez reforce a idéia de que são múltiplos os objetos da Ciência da Informação, porque são múltiplos os fatos sociais geradores e os blocos temáticos constituídos ou a constituir-se. Uma pista neste sentido, pode ser a afirmação de Saul Herner, conforme Moraes (2002, s. p.), sobre a constituição da Ciência da Informação. Diz ele: "ela é o produto da convergência da Biblioteconomia, da Ciência da Computação e dos cartões perfurados, da pesquisa e desenvolvimento, da documentação, do trabalho de resumo e indexação, da comunicação científica, da ciência do comportamento, das publicações macro e micro e das ciências das imagens".

É em face dessa diversidade factual e de formas de interpretar o campo da Ciência da Informação, que se pode propor para discussão que mais que buscar grandes objetos unificadores do campo deve-se percebê-lo como constituído a partir de fenômenos ou blocos temáticos determinados pelas necessidades coletivas, a desdobrar-se em tantos e fragmentados objetos de pesquisa quanto os exigidos pelo funcionamento da realidade humana e conforme situação de tempo e espaço. Assim, propõe-se aqui, para os pesquisadores em Ciência da Informação no Brasil, que avaliemos se devemos investir na construção sistemática de objetos de pesquisa a partir dos seguintes blocos temáticos:

. Decodificação de conhecimento social (fato social determinante: Leitura);

. Interação social permanente (fato social determinante: Comunicação);

- Produção interpretativa e empírica como resposta a necessidades coletivas (fato social determinante: Conhecimento)

- Aquisição de conhecimento simbólico controlado socialmente (fato social determinante: Educação)

. Estoque de conhecimento (fato social determinante: Memória)

. Ordenamento e controle das necessidades coletivas (fato social determinante: Política)

- Regulação de acesso material à memória, educação, conhecimento e comunicação (fato social determinante: Economia)

Estes fenômenos ou blocos temáticos, por si sós, são enfáticos quanto à necessidade da atuação multidisciplinar, posto que os fatos sociais que os determinam perpassam por toda a existência humana e são, dessa maneira, determinantes também de blocos temáticos em outros campos de investigação. 


\section{OBJETOS ESTUdADOS NA CIÊNCIA DA INFORMAÇÃO: O MOMENTO BRASILEIRO}

A pesquisa em Ciência da Informação no Brasil se estabelece a partir dos anos 1970 no quadro geral do desenvolvimento do campo biblioteconômico norte e latino americanos. Contudo, a preocupação com seu ensino nas escolas de biblioteconomia já aparecia na década precedente. Licea de Arenas e Arenas Vargas (2000, p. 86) reportam-se a autores norteamericanos para afirmar que a pesquisa em Biblioteconomia começou a ser tratada como de interesse nos anos 1920, mas carecia de desenvolvimento de metodologia científica. Menciona que reuniões de estudo sobre a preparação dos bibliotecários na América Latina realizadas em Medellín, Colômbia de 1963 a 1965, indicavam a necessidade de constar nos currículos das escolas da região a disciplina Metodologia de Pesquisa, com a seguinte ênfase "Introdução aos problemas e a metodologia do estudo e da pesquisa. Preparação de trabalhos escritos, monografias e teses. Técnicas da compilação estatística".

No Brasil, rigorosamente, a pesquisa em Ciência da Informação tem sido uma responsabilidade dos programas de pós-graduação e o pioneirismo se dá com a criação do Curso de Mestrado em Ciência da Informação, pelo hoje IBICT (Instituto Brasileiro de Informação Científica e Tecnológica), em 1970, em período histórico restritivo de liberdade de escolhas temáticas e metodológicas (BUFREM, 1997). Desse modo, os objetos estudados têm correspondido sem grandes divergências do mapeamento que foi, com pequena diversidade de expressão entre os autores, resgatado na seção 2 deste artigo e que de certa maneira são articulados pelas linhas de investigação dos programas de mestrado e doutorados existentes no campo no país. Em artigo de Smit; Dias e Souza (2002), pode-se identificar nos seis programas existentes e funcionando até $2001^{*}$ na PUCCAMP, UFBA, UFMG, UFRJIBICT, UNB e UNESP (Marília, SP) as seguintes linhas:

. Administração de serviços de bibliotecas, arquivos e informação

. Comunicação da informação científica, tecnológica e para negócios

. Configurações sociais e políticas da informação

. Estruturas e linguagens da informação

. Formação e mercado de trabalho do profissional da informação

\footnotetext{
* A partir de junho de 2003 teve início um novo Programa de Pós-Graduação em Ciência da Informação Mestrado - na Universidade Federal de Santa Catarina, reconhecido pela Portaria 1584/MEC/2003, de 20/06/2003. Nesse Programa foram constituídas as linhas de investigação: Fluxos de Informação e Profissionais da Informação.
} 
. Gestão da informação

. Gestão de serviços de informação

. Informação e contextos

. Informação e sociedade

. Informação e tecnologia

. Informação gerencial e tecnológica

. Informação orgânica

. Informação para indústria e negócios

. Organização da informação

. Planejamento e administração de programas de leitura

. Planejamento e gestão da informação e do conhecimento

. Processamento e tecnologia da informação

. Processos e linguagens de indexação

. Produção e disseminação de informação nas organizações

. Teoria, epistemologia, interdisciplinaridade

. Tratamento da informação e bibliometria

Naturalmente, as ementas de cada linha fazem um detalhamento que dá para enxergar melhor o alcance pretendido por cada uma acerca dos objetos de pesquisa que constitui. De outro lado, a literatura publicada em periódicos do campo traz resultados de pesquisa com objetos muito diversos o que serve para mostrar as amplas possibilidades que estão abertas a qualquer investigador iniciante, seja em termos dos conteúdos desses objetos seja em termos das metodologias que vêm empregando. Assim, por exemplo, são encontrados estudos cujos objetos dizem respeito à produção da literatura; produtividade de autores, títulos de dissertações e teses, atuação profissional, etc. em geral podendo ser classificados quanto aos objetivos pretendidos em exploratórios ou descritivos. Quanto à sua classificação em termos de metodologia há uma predominância da abordagem quantitativa, sobretudo com o emprego da bibliometria e cienciometria, mas também se verifica uma forte presença na última década dos estudos quali-quantitativos e qualitativos por conta, sobretudo, das linhas informação e sociedade; teoria, epistemologia, interdisciplinaridade; Configurações sociais e políticas da informação e Informação e contextos, ora mantidas por alguns programas. 


\section{AS POSSIBILIDAdES PEDAGÓGICAS PARA O ENSINO DE METODOLOGIA DA PESQUISA CIENTÍFICA EM CIÊNCIA DA INFORMAÇÃO}

A questão principal que agora se coloca é o que, então, deve ser tratado e como se pode fazê-lo nos cursos de graduação e pós-graduação em Ciência da Informação. Uma observação inicial é de que não pode ser mais ou somente o conteúdo sugerido nas Reuniões de Medellín, de 1963 a 1965, dantes mencionado, ou aquele que está estruturado no livro de Goldhor (1973) e também não pode ser somente a aula magistral, expositiva, até porque nestas três últimas décadas houve mais de uma onda de intensa atualização de todas as tecnologias as quais modificaram vários modos de realizar a atividade de pesquisa científica de âmbito social. Houve também o surgimento de um grande número de novos problemas que adensaram, substantivamente, os fatos sociais que constituem os blocos temáticos da Ciência da Informação.

De outro lado há, em termos didáticos e pedagógicos, algumas considerações que se deve ter em conta quando se fala em ensino e aprendizagem da ciência e da informação científica no ensino superior. Numa abordagem mais do que fundamental, MARQUES (1997) chama a atenção para o fato de que a pesquisa começa com a escrita que, por sua vez, exige a leitura. Isso quer dizer que a educação científica e a formação científica em Ciência da Informação dependem da qualidade garantida pela educação básica ofertada aos alunos dos cursos que fazem parte do campo. Essa garantia tem relação direta com a infra-estrutura de informação e comunicação que se ofertou a professores e alunos, com o tempo que se lhes destinou para o uso competente dessa infra-estrutura e com a competência que adquiriram para assimilar, transformar e aplicar as potencialidades de absorção dos novos desafios colocados pelas necessidades coletivas. Além disso, se esboça uma consciência, no campo da Ciência da Informação, de que ocorre um processo dinâmico de mão-dupla na relação professor e aluno que se envolvem com o ensino e pesquisa o qual é rico para ambos e para o próprio crescimento da ciência no país (FREIRE e GARCIA, 2002).

Nisso, tem-se outras duas considerações para resgatar nesta discussão, e ambas dizem respeito aos dilemas e problemas do ensino de conteúdos que cabem em rótulos disciplinares diversos: Prática de Pesquisa, Metodologia da Pesquisa, Metodologia Científica, Métodos de Pesquisa, etc.. A primeira consideração é relativa ao ensino da prática de pesquisa, tema tratado por Senra (2000) e a segunda diz respeito a "como se aprende a ciência" e "como seria um modelo pedagógico para a aprendizagem da ciência”, discussão tratada por Gutierrez Vargas (2002). 
Em seu texto, Senra apresenta uma proposta abrangente e densa. Mas, parece a uma primeira análise, que tem problemas que passam pela base intelectual suposta de seus alunos. Embora o autor demonstre consciência da necessidade da leitura, ele exibe em seu texto a percepção de que as leituras "heterodoxas" que sugere, e são leituras pouco comuns por se tratar de alguns romances que indica ao longo da execução de seu plano de ensino, não são lidas pelos alunos de sua disciplina. Sua proposta no todo é muito ampla. Os conceitos que procura apresentar, as estratégias que pretende desenvolver, os objetivos que deseja alcançar são de excelência qualitativa, contudo constituem conteúdo e forma de um curso muito mais amplo e também introdutório, que instrui a formação de metodologistas. Apesar de proposto para o nível de pós-graduação, nos procedimentos para a formação de juízo crítico e para a formação da competência argumentativa já estaria cumprindo, provavelmente, o desejável para o ambiente formativo no qual se propõe a atuar. Em tudo o mais, parece estar desejando resgatar a ausência no ensino médio brasileiro de formação de conteúdos sociológicos e filosóficos, fruto de uma política governamental que impede a apresentação destes conhecimentos naquele nível. Neste aspecto, o autor, como todos os demais docentes, em quase todos os campos, é um experimentador de possibilidades que se move na proporção em que co-move suas turmas. Esta consciência da experimentação, concebida como resultante da formulação das respostas possíveis para as necessidades coletivas com que se defronta no convívio com os alunos parece ser o grande diferencial de sua prática de ensino de pesquisa. Uma outra visão, também aberta à discussão, é a apresentada por Gutiérrez Vargas (2002).

Para Gutiérrez Vargas (2002), há uma preliminar a ser considerada, isto é, a de que existem cinco etapas na metodologia contemporânea da Ciência: 1 - a acumulação e elaboração de dados empíricos; 2 - a construção e o desenvolvimento de uma teoria; 3 - a explicação de dados empíricos conhecidos; 4 - a predição de novos dados com base na teoria elaborada; e 5 - a confirmação da teoria. E acrescenta, "Este procedimento depende da palavra impressa porque forma parte de um registro público permanente de conceitos, teorias, observações, cálculos e resultados para poder referir-se a eles” (p. 200). Essa observação tem coerência com o pensamento de Durkheim no sentido de que ele vê as representações coletivas como parte do arsenal de meios e como respostas às perguntas construídas a partir das necessidades humanas. Neste aspecto, há aí um mundo retórico, do discurso inacabado ou, de outro lado, pelo olhar Habermasiano, do agir comunicativo (HABERMAS, 1999), em que o homem se move pela transação permanente que, pode-se pensar, é provocada pelos fatos sociais. Nesse aspecto, o Cientista da Informação, se moveria a partir dos fatos: Leitura, Comunicação, Conhecimento, Educação, Memória, Política e Economia. 
Em Gutiérrez Vargas (2002), pode-se encontrar algumas percepções que expressam essa clareza. Diz que: "a formação dos futuros profissionais tem que considerar a ciência como uma cultura (...) [e que] é necessário assimilar uma ideologia, uma forma de trabalhar e interpretar o mundo (...) que compartilha com a comunidade científica. Processos de trabalho, informação científica, perguntas científicas, teorias e conceitos (...) técnicas de questionamento e interpretação do homem e da natureza; arbitragens e consensos de validação de resultados, formas de comunicação e os produtos de seu trabalho" (p. 203). É, portanto, o mundo da palavra, da palavra escrita, que mobiliza a ação científica. E o resultado é a ciência. Em Senra o dilema é como formar o cientista. Mas formar o cientista é formar escritores de uma escritura específica. E formar escritores depende de se ter formado leitores em todas as formas pela qual se manifesta a natureza e a humanidade.

Neste aspecto, verifica-se que há convergência entre o trabalho realizado e relatado por Senra e as idéias apresentadas por Gutiérrez Vargas. Coerente com isso, no Curso de Bacharelado em Biblioteconomia da UFSC faz-se um esforço redobrado visando formar entre os estudantes uma competência, dentro dos limites que os diversos níveis de ensino permitem, para a escrita. Então, é possível perceber que as possibilidades pedagógicas para o ensino de Metodologia da Pesquisa Científica em Ciência da Informação estão ancoradas no fortalecimento da educação fundamental e média de cada país que, por sua vez, está a depender da infra-estrutura de leitura de diversas mídias que possam ser disponibilizadas nas escolas, nos bairros ao serviço de toda e qualquer nação. Isto impõe questões para serem pensadas: dá para se fazer uma projeção, a partir dos investimentos realizados em ensino fundamental e médio e nas infra-estruturas em que atuam os Cientistas da Informação, de em quanto tempo o Brasil terá uma ciência competitiva com países de seu porte econômico e semelhante potencial de recursos naturais? Poderia ser esta uma questão geradora objetos de trabalho investigativo na Ciência da Informação? Onde se cruza, no ensino da Ciência da Informação brasileira, contexto e texto?

\section{REFERÊNCIAS}

BARRETO, Aldo de Albuquerque. Entrevista concedida a Leonardo Melo em outubro de 2002. Leia e Pense. Disponível em: http://www.leiaepense.kit.net

BERGER, Peter; LUCKMANN, Thomas. A construção social da realidade: tratado de Sociologia do conhecimento. 6. ed. Petrópolis: Vozes, 1985. 247 p. 
BUFREM, Leilah Santiago. O contexto histórico da pesquisa em informação no Brasil. Transinformação, Campinas, SP, v. 9, n.1, jan./abr. 1997. Disponível em http://www.puccamp.br/ biblio/bufrem91.html. Acesso em 23/05/2003.

BUTLER, Pierce. Introducción a la biblioteconomia. México, DF; Pax-México, 1971. 182 p.

CAMPOS, Maria Luiza de Almeida. As cinco leis da biblioteconomia e o exercício profissional. Disponível em http://www.conexaorio.com/biti/mluiza/index.htm. Acesso em $18 / 09 / 2002$.

CARVALHO, Eduardo Costa. A natureza social da ciência da informação. In: PINHEIRO, Lena Vânia Ribeiro (org.). Ciência da informação, ciências sociais e interdisciplinaridade. Brasília, DF; Rio de Janeiro: IBICT, 1999. p. 51-63.

DIAS, Eduardo Wense. O específico da ciência da informação. In: AQUINO, Miriam de Albuquerque (org.). O campo da ciência da informação: gênese, conexões e especificidades. João Pessoa: Ed. Universitária, 2002. p. 87-99.

DURKHEIM, Émile. As regras do método sociológico. São Paulo: Martin Claret, 2003. 155 p.

FREIDSON, Eliot. Renascimento do profissionalismo; teoria, profecia e política. São Paulo: Ed. USP, 1998.

FREIRE, Gustavo Henrique; GARCIA, Joana Coeli Ribeiro. Avaliação científica: a visão do pesquisador. Informação \& Sociedade: estudos, João Pessoa, v. 12, n. 2, 2002. Disponível em http://www.informacaoesociedade.ufpb.br/issuev12n202.html. Acesso em 23/05/2003.

GIDDENS, Anthony; TURNER, Jonathan. (org.). Teoria social hoje. São Paulo: Ed. UNESP, 1999. 609 p.

GIL, Antonio Carlos. Como elaborar projetos de pesquisa. 3. ed. São Paulo: Atlas, 1996. $159 \mathrm{p}$.

GOLDHOR, Herbert. Pesquisa científica em biblioteconomia e documentação. Brasília, DF; VIPA, 1973. 221 p.

GONZÁLEZ DE GÓMEZ, Maria Nélida. Metodología da pesquisa no campo da ciência da informação. R. Biblioteconomia Brasília, v. 23/24, n. 3, especial, p. 333-346, 1999/2000.

GUTIERREZ VARGAS, Martha Elba. El aprendizaje de la ciencia y de la información científica en la educación superior. Anales de documentación, n. 5, 2002. Disponivel em http://www.um.es/fccd/anales/ad05/ad0510.pdf

HABERMAS, Jurgen. Teoria de la acción comunicativa; racionalidad de la acción y racionalización social. Madrid: Taurus, 1999. 2. v.

HAGUETTE, Tereza Maria Frota. Metodologias qualitativas na sociologia. 5. ed. Petrópolis: Vozes, 1997. 224 p. 
LIBRARY TRENDS. Qualitative research. v. 46, n. 4, Spring 1998.

LICEA DE ARENAS, Judith; ARENAS VARGAS, Miguel. La formación de comunidades científicas en bibliotecología y ciencia de la información. Anales de documentación, n. 3, 2000, p. 81-91.

MARKERT, Werner. Las estrategias de formación de recursos humanos de empresas multinacionales en América Latina y el Caribe. Santiago: CEPAL, 1999.

MARQUES, Mario Osório. Escrever é preciso: o princípio da pesquisa. Ijuí: Ed. UNIJUI, 1997. $140 \mathrm{p}$.

MINAYO, Maria Cecília de Souza (org.). Pesquisa social: teoria, método e criatividade. 20. ed. Petrópolis: Vozes, 2002. 80 p.

MIRANDA, Antonio; BARRETO, Aldo de Albuquerque. Pesquisa em Ciência da Informação no Brasil: síntese e perspectiva. R. Biblioteconomia Brasília, v. 23/24, n. 3, especial, p. 277$292,1999 / 2000$.

MORAES, Alice Ferry de. Os pioneiros da ciência da informação nos EUA. Informação \& Sociedade: estudos, João Pessoa, v. 12, n. 2, 2002. Disponível em http://www.informacaoesociedade.ufpb.br/issuev12n202.html. Acesso em 23/05/2003.

MUELLER, Suzana Pinheiro Machado; MIRANDA, Antonio; SUAIDEN, Emir José. A pesquisa em ciência da informação no Brasil - análise dos trabalhos apresentados no IV Enancib, Brasília, 2000. R. Biblioteconomia Brasília, v. 23/24, n. 3, especial, p. 293-308, $1999 / 2000$.

MUELLER, Suzana Pinheiro Machado. A pesquisa em ciência da informação no contexto das ciências humanas. DataGramaZero: Revista de Ciência da Informação, Rio de Janeiro, v.1, n.6, dez. 2000. Disponível em http://www.dgz.org.br/dez00/Art 05.htm

PINHEIRO, Lena Vânia Ribeiro. Campo interdisciplinar da ciência da informação: fronteiras remotas e recentes. In: __. Ciência da informação, ciências sociais e interdisciplinaridade. Brasília, DF; Rio de Janeiro: IBICT, 1999. p. 155-182.

Infra-estrutura da pesquisa em ciência da informação no Brasil. R. Biblioteconomia Brasília, v. 23/24, n. 3, especial, p. 367-390, 1999/2000.

RAMIREZ LEYVA, Elza M. Investigación bibliotecológica y desarrollo de la sociedad de la información en America Latina. R. Biblioteconomia Brasília, v. 23/24, n. 3, especial, p. 309$328,1999 / 2000$.

RANGanathan, S. R. The Colon Classification. New Brunswick, N. J.: Rutgers University, 1965.

RODRIGUES JR., Léo. Sociologia do conhecimento: aspectos clássicos e contemporâneos. In: BAUMGARTEN, Maíra. (org.) A era do conhecimento: Matrix ou Ágora? Porto Alegre/Brasília: Ed. Universidade - UFRGS/Ed. UnB, 2001. p. 21-44. 
SENRA, Nelson Castro. O ensino da prática de pesquisa, vivência e consciência. DataGramaZero: Revista de Ciência da Informação, Rio de Janeiro, v.1, n.6, dez. 2000. Disponível em http://www.dgz.org.br/dez00/Art_01.htm

SMIT, Johanna W.; DIAS, Eduardo Wense; SOUZA, Rosali Fernandez de. Contribuição da Pós-graduação para a Ciência da Informação no Brasil: uma visão. DataGramaZero: Revista de Ciência da Informação, Rio de Janeiro, v.3, n.6, dez. 2002. Disponível em http://www.dgz.org.br/dez02/Art 04.htm.

\begin{abstract}
This article results of bibliographical, exploratory and qualitative research. Its argues that three approaches are gifts in the educational process of discipline of the Scientific Research Methodology in Information Science. They are the social facts of the Information Science, the types of the research and the social theory. It sees that the pedagogical possibilities of the education of Scientific Methodology in Information Science are related with the practical one of the writing which depends on the practical one of the reading.
\end{abstract}

KEYWORDS: Education of scientific Methodology. Research in Information Science. Scientific object in the Information Science. 